\title{
Malignancy incidences by glycemic control among diabetic patients
}

\author{
Daiki Kobayashi ${ }^{1,2,3}$, Nagato Kuriyama ${ }^{4}$, Keita Hirano ${ }^{5}$, Osamu Takahashi ${ }^{1,2}$ and Hiroshi Noto ${ }^{6}$ \\ 'Division of General Internal Medicine, Department of Medicine, St. Luke's International Hospital, Tokyo, Japan \\ ${ }^{2}$ Department of Epidemiology, St. Luke's International University Graduate School of Public Health, Tokyo, Japan \\ ${ }^{3}$ Fujita Health University, Toyoake, Japan \\ ${ }^{4}$ Department of Epidemiology for Community Health and Medicine, Kyoto Prefectural University of Medicine, Kyoto, Japan \\ ${ }^{5}$ Department of Nephrology, Kyoto University Graduate School of Medicine, Kyoto, Japan \\ ${ }^{6}$ Department of Endocrinology, St. Luke's International Hospital, Tokyo, Japan
}

Correspondence should be addressed to D Kobayashi: daikoba@luke.ac.jp

\begin{abstract}
Background: The aim of this study was to evaluate the difference in malignancy incidence by evaluating time-dependent $\mathrm{HbA} 1 \mathrm{c}$ levels among diabetic patients in a longitudinal study.

Methods: We conducted a retrospective longitudinal study at large academic hospital, Tokyo, Japan, from 2006 to 2016. We included all diabetic patients who were 50 years or older and who underwent health check-ups at the Center for Preventive Medicine. Those patients with a prior history of malignancies were excluded. We categorized patients into five groups on the basis of HbA1c measurements: $<5.4,5.5-6.4,6.5-7.4,7.5-8.5,>8.5 \%$. Our primary outcome was the development of any types of malignancy. Longitudinal analyses by a mixed effect model with time-dependent $\mathrm{HbA} 1 \mathrm{c}$ levels were applied in order to take into account fluctuations in $\mathrm{HbA} 1 \mathrm{c}$ levels within the same patient. Results: In total, 2729 participants were included in this study, where the mean age was 62.6 (standard deviation (s.D.): 7.8) and 2031 (74.4\%) were male. The mean disease duration of diabetes was 7.6 (s.D.: 7.6) years, and $1688(61.8 \%)$ were prescribed medications. Median follow-up was 1443.5 (interquartile range (IQR): 2508) days and $376(13.8 \%)$ developed malignancies. Compared to the reference range of $\mathrm{HbA} 1 \mathrm{C}$ (5.5-6.4\%), the odds ratios for developing malignancies among the other $\mathrm{HbA} 1 \mathrm{c}$ level groups were similar and not statistically different (OR: 0.98, 95\% Cl:0.31-3.15 (for HbA1C $<5.4 \%$ ); OR: $0.88,95 \%$ Cl: 0.69-1.12 (for HbA1c 6.5-7.4\%); OR: 0.88, 95\% Cl: 0.64-1.22 (for HbA1c 7.5-8.4\%); OR 1.07, 95\% Cl: 0.70-1.66 (for HbA1c >8.5\%)).

Conclusion: In our study, there was no association between glycemic control and the development of future malignancies. Compared to very strictly controlled $\mathrm{HbA1c}$ levels, both excessive control and good or bad control had a statistically similar risk of developing malignancies.
\end{abstract}

\author{
Key Words \\ - diabetes \\ - glycemic control \\ - malignancy \\ - longitudinal analysis
}

\section{Introduction}

Previous systematic reviews and meta-analyses have reported that diabetic patients have a higher risk of developing malignancies compared to nondiabetic patients $(1,2,3,4)$. Based on these reports, diabetic patients may have an approximately $20 \%$ increased risk of developing any type of cancer (3). Among diabetic patients, risk was reported for each type of cancer. For instance, previous studies have reported a higher risk of colon cancer (hazard ratio (HR): 1.40), hepatocellular carcinoma (HR: 1.97), pancreatic cancer (HR: 1.85) and cholangiocarcinoma

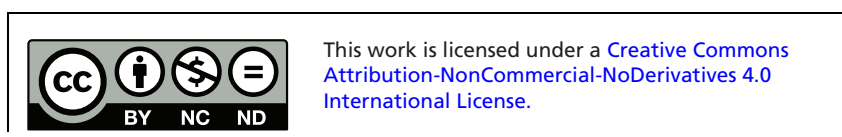


(HR: 1.66) $(3,5,6,7,8)$. Other malignancies, such as esophageal cancer, gastric cancer or lung cancer, may have no association with diabetes $(9,10,11)$. In contrast, specific cancers, such as prostate cancer, have been reported to have an inverse relationship to diabetes $(12,13)$. Thus, this previous research suggests that there could be certain associations between diabetes and malignancies.

Although the association of diabetes with malignancies among diabetic patients compared to nondiabetic patients has been well evaluated, the differences in the incidence of malignancies among diabetic patients in terms of the level of glycemic control are still controversial. Previous meta-analyses and systematic reviews, which included four randomized control trials $(14,15,16,17)$, reported no difference in malignancy development between intensively treated and standardly treated diabetic patients, even in subanalyses (18). These randomized control trials may have several limitations: malignancies were not the primary outcomes, they were unblinded and there was insufficient follow-up. In contrast, some observational studies have reported that diabetic patients who had higher hemoglobin A1c (HbA1c) levels had higher incidence rates of malignancies compared to those who had lower HbA1c levels $(19,20,21,22)$. In addition to the controversy regarding the association of glycemic control with malignancies based on previous reports, these studies did not take into account the changes in glycemic control. In other words, HbA1c levels can fluctuate over time in the same person, so a single measurement of HbA1c levels would be insufficient to evaluate the true association between glycemic control and the development of malignancies. Moreover, no previous study has evaluated the effect of excessive glycemic control, such as an HbA1c level of $5.5 \%$ or lower, on the development of malignancies.

The generalized linear model (GML) is a statistical technique that can address repeated measures. As a result, we can measure the effect of treatment/exposure at different time points. Recently, this technique has been applied in many clinical research studies for repeated measurements (23). By using this technique, we can consider the true effect of fluctuating glycemic control on the development of malignancies.

The aim of this study is to evaluate the difference in malignancy incidence by time-dependent HbA1c levels among diabetic patients.

\section{Methods}

We conducted a retrospective longitudinal study at St. Luke's International Hospital, Tokyo, Japan, from 2006 to 2016 . We included diabetic patients who were 50 years or older male and female and who underwent voluntary health check-ups at the Center for Preventive Medicine at the hospital at baseline. Diabetic patients were defined as those who reported being diagnosed with diabetes prior to the hospital visits or who were treated for diabetes at the hospital. These patients also reported their disease duration and the prescriptions they took for diabetes. We included patients if they were diagnosed as diabetes at baseline and did not exclude them due to short or long duration of disease. Those patients who had histories of malignancies prior to their first visit were excluded. However, there were no other exclusion criteria, such as risk factors. We compared the incidence of future malignancies using hemoglobin A1c levels as a longitudinal measure of glycemic control. All data were extracted from electronic medical records.

The St Luke's International Hospital Ethics Committee Institutional Review Board (IRB) approved this study (17-R022). The IRB waived to obtain written consent from each patient, because this study was a retrospective design. However, we excluded all patients who signed opt out agreements for their anonymized data to be used in research.

\section{Hemoglobin A1c measurement}

Hemoglobin A1c (HbA1c) was measured for all participants as a part of their health check-ups at each visit. HbA1c, which was measured by Japanese diabetes society values, was converted to that of the National Glycohemoglobin Standardization Program value (24). We categorized each HbA1c measurement into five groups: <5.4, 5.5-6.4, $6.5-7.4,7.5-8.5$ and $>8.5 \%$ (25). We considered $5.5-6.4 \%$ of HbA1c as the reference group. Because HbA1c levels fluctuate over time in each patient, we applied longitudinal analyses with HbA1c levels as the time-dependent variable to take into account the change in HbA1c levels over time. The HbA1c measurement interval differed for each participant, with most participants revisited from 6 months to 2 years later.

\section{Malignancy}

The development of any malignancies, which were coded C00-D49 by the International Classification of Diseases (ICD)-10, was included as the primary outcome (26). Malignancy was diagnosed by a physician based on both clinical and pathological findings in the hospital. In addition to the diagnosis at the hospital, we obtained 
information about those malignancies that were diagnosed in other hospitals based on participants' reports. For those patients who developed malignancies multiple times, only information about the first malignancy was used for analysis.

\section{Data collection}

We obtained information about patients' demographics and health habits based on self-reporting as a part of the health check-ups. In terms of alcohol use, we divided the participants into three categories: abstainers, social drinkers and regular drinkers. Smoking status was categorized into never, former and current. Exercise was also divided into four categories: almost none, 2-3 times a week, 4-5 times a week and almost all days.

\section{Statistical methods}

We conducted cross-sectional analyses of participants' characteristics at the first visit for each participant by baseline HbA1c category. Chi-square tests were applied to categorical variables, and analysis of variance was used for continuous variables. Then, longitudinal analyses were performed with the data from 2006 to 2016 to investigate the longitudinal association between HbA1c levels and the future development of malignancies. Adjusted odds ratios for future malignancies were obtained with the model of the binomial family with the logit link function. To account for repeated measurements of participants and random effects of observations, we applied a mixed effect model with an unstructured working correlation. To take changes in HbA1c category over time into consideration, we used HbA1c levels as time-dependent variables in the longitudinal analyses. Two sensitivity analyses were conducted to confirm the results by applying different covariates to the models and focusing on those patients who developed malignancies 2 years after their first visit. In the sensitivity analysis, by applying different covariates, we included HbA1c category and patients' demographics in model 1, patients' diabetes disease duration and treatment status were added to model 2 in addition to model 1 variables, health habits were added to model 3 in addition to model 1 variables and all the above variables were included in model 4 . In the sensitivity analysis, by focusing on those patients who developed malignancies 2 years after their first visit, we excluded those patients who developed malignancies within 2 years after their first visit from the analyses in order to exclude asymptomatic cancer, which was pre-existing but had not been detected at the first visit.
All analyses were performed in 2018 using SPSS 24.0J statistical software (IBM Japan) and STATA 14 (STATA Corp.).

\section{Results}

In total, 2729 participants were included in this study, where the mean age was 62.6 (standard deviation (s.D.): 7.8) and 2031 (74.4\%) were male. The mean disease duration of diabetes was 7.6 (s.D.: 7.6) years, and 1688 (61.8\%) were prescribed medications (Table 1). At baseline, the proportion of males to females was higher among those with very low (less than $5.4 \%$ ) or high $(7.5 \%$ or more) HbA1c levels than among those with middle (5.5-7.4\%) HbA1c levels. The mean disease duration of diabetes was longer among those with very low (less than $5.4 \%)$ or high (7.5\% or more) HbA1c levels than among those with middle (5.5-7.4\%) HbA1c levels. Those with very low HbA1c level were more regular drinkers and current smokers; they also exercised less.

The median follow-up was 1443.5 (interquartile range (IQR): 2508) days, and the median number of health check-ups was 4.0 (IQR: 6.0) times. During follow-up, 376 (13.8\%) developed malignancies. Of these malignancies, $88(23.4 \%)$ were prostate cancer, followed by 68 (18.1\%) were gastric cancer and 40 (10.6\%) were lung cancer. Table 2 shows the list of all malignancies. Table 3 shows the results from the mixed-effect model and sensitivity analyses. Compared to the reference range of HbA1c (5.5-6.4\%), the odds ratios for developing malignancies among the other HbA1c level groups were similar and not statistically different (in model 1, OR: 0.98, 95\% CI: 0.31-3.15 among those with HbA1c levels <5.4\%; OR: 0.88, 95\% CI: 0.69-1.12 among those with HbA1c levels of $6.5-7.4 \%$; OR: $0.88,95 \% \mathrm{CI}$ : $0.64-1.22$ among those with HbA1c levels of 7.5-8.4\%; OR 1.07, 95\% CI: 0.70 1.66 among those with HbA1c levels $>8.5 \%$ ).

In the sensitivity analyses with different covariates, all odds ratios of other HbA1c categories were not significantly different from the reference category (the range of ORs: 0.98-1.01 among those with HbA1c levels $<5.4 \%$; the range of ORs: $0.88-0.90$ among those with HbA1c levels of $6.5-7.4 \%$; the range of ORs: $0.88-0.92$ among those with HbA1c levels of 7.5-8.4\%; the range of ORs: 1.07-1.12 among those with HbA1c levels >8.5\%). In the sensitivity analyses excluding those who developed malignancies within 2 years after their first visit $(n=123)$, all HbA1c categories had similar odds for developing malignancies comparing to the reference category. This work is licensed under a Creative Commons
Attribution-NonCommercial-NoDerivatives 4.0 International License. 


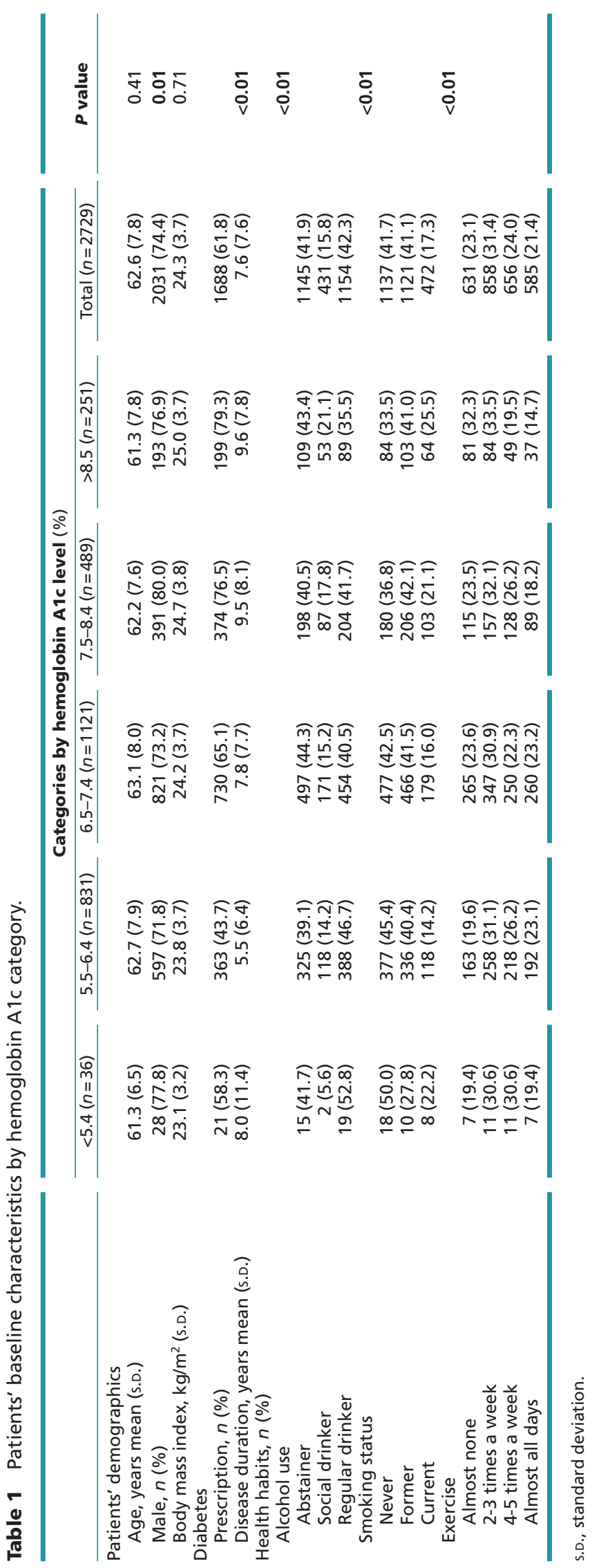

https://ec.bioscientifica.com https://doi.org/10.1530/EC-18-0355
Table 2 The list of all malignancies developed in the study period.

\begin{tabular}{|c|c|c|}
\hline Malignancy & $\begin{array}{c}\text { Number of } \\
\text { patients }\end{array}$ & Percentage \\
\hline Prostate cancer & 88 & 23.4 \\
\hline Gastric cancer & 68 & 18.1 \\
\hline Lung cancer & 40 & 10.6 \\
\hline Colorectal cancer & 38 & 10.1 \\
\hline Esophagus cancer & 30 & 8 \\
\hline Breast cancer & 21 & 5.6 \\
\hline Bladder and ureteral cancer & 18 & 4.8 \\
\hline Liver cancer & 14 & 3.7 \\
\hline Others & 14 & 3.7 \\
\hline Pancreatic cancer & 8 & 2.1 \\
\hline Kidney cancer & 7 & 1.9 \\
\hline Lymphoma & 6 & 1.6 \\
\hline Skin cancer & 6 & 1.6 \\
\hline Bile duct and gallbladder cancer & 4 & 1.1 \\
\hline Leukemia & 4 & 1.1 \\
\hline Cervical cancer & 3 & 0.8 \\
\hline Mediastinal neoplasm & 2 & 0.5 \\
\hline Duodenal cancer & 2 & 0.5 \\
\hline Endometrial cancer & 1 & 0.3 \\
\hline Thyroid cancer & 1 & 0.3 \\
\hline Ovarian cancer & 1 & 0.3 \\
\hline
\end{tabular}

\section{Discussion}

In our longitudinal study, we demonstrated that the incidence of malignancies was not associated with glycemic control among middle-aged and elderly diabetic patients. Sensitivity analyses with different covariates supported this result. This result is supported by the findings of previous randomized control trials but contradicts the findings of previous observational studies. This discrepancy may come from the difference of inclusion/exclusion criteria and duration of disease between our study and others. Moreover, our study shows that even those patients with excessively low HbA1c may have a risk of developing malignancies similar to those patients with good HbA1c control, a finding that has not been evaluated in previous studies.

The mechanisms by which there is no association between glycemic control and future malignancy was unclear. Previous studies that have investigated the association of glycemic control with the development of malignancies among diabetic patients did not discuss the mechanisms for positive or no association (14, 15, 16). Several studies focusing on the association between diabetes and malignancies have advanced possible mechanisms. One possibility is that $H$. pylori infection may play an important role as a cofactor for diabetes and the development of gastric cancer (27). Although the 
Table 3 The adjusted odds ratios for developing malignancies by hemoglobin A1c category from longitudinal analyses using a mixed effect model and two sensitivity analyses $(n=2729$, total number of hemoglobin A1c measurements $=14,179$ for the analyses with all participants; $n=2606$ total number of hemoglobin A1c measurements $=13,894$ for the analyses excluding those who developed malignancies within two years after their first visit).

\begin{tabular}{|c|c|c|c|c|}
\hline \multirow[b]{2}{*}{ Hemoglobin A1c, \% (No. of measurements, \%) } & \multicolumn{4}{|c|}{ Adjusted odds ratios for the development of malignancies ( $95 \%$ confidence interval) } \\
\hline & Model 1 & Model 2 & Model 3 & Model 4 \\
\hline \multicolumn{5}{|l|}{ All participants } \\
\hline$<5.4(132,0.9 \%)$ & $0.98(0.31-3.15)$ & $0.99(0.31-3.19)$ & $0.99(0.31-3.19)$ & $1.01(0.32-3.24)$ \\
\hline $5.5-6.4(4174,29.4 \%)$ & Reference & & & \\
\hline $6.5-7.4(6488,45.8 \%)$ & $0.88(0.69-1.12)$ & $0.90(0.70-1.16)$ & $0.88(0.69-1.13)$ & $0.90(0.70-1.16)$ \\
\hline $7.5-8.4(2364,16.7 \%)$ & $0.88(0.64-1.22)$ & $0.92(0.66-1.29)$ & $0.89(0.64-1.23)$ & $0.92(0.66-1.30)$ \\
\hline$>8.5(1021,7.2 \%)$ & $1.07(0.70-1.66)$ & $1.12(0.72-1.76)$ & $1.05(0.68-1.63)$ & $1.10(0.70-1.73)$ \\
\hline \multicolumn{5}{|c|}{ Excluding those who developed malignancies within two years after their first visit } \\
\hline$<5.4(127,0.9 \%)$ & $0.57(0.07-4.43)$ & $0.59(0.08-4.63)$ & $0.55(0.07-4.30)$ & $0.58(0.07-4.53)$ \\
\hline $5.5-6.4(4085,29.4 \%)$ & Reference & & & \\
\hline $6.5-7.4(6369,45.8 \%)$ & $0.86(0.63-1.19)$ & $0.92(0.66-1.28)$ & $0.87(0.63-1.20)$ & $0.92(0.66-1.28)$ \\
\hline $7.5-8.4(2319,16.7 \%)$ & $0.89(0.58-1.36)$ & $0.98(0.63-1.53)$ & $0.89(0.58-1.37)$ & $0.98(0.63-1.53)$ \\
\hline$>8.5(994,7.2 \%)$ & $0.97(0.52-1.82)$ & $1.11(0.59-2.09)$ & $0.96(0.51-1.81)$ & $1.09(0.57-2.07)$ \\
\hline
\end{tabular}

Model 1 included a time variable and patients' demographic information, such as age and gender, for adjustment. Model 2 included information about diabetes, such as duration of disease and prescriptions, for adjustment in addition to model 1. Model 3 included health habits, such as alcohol use, smoking status, exercise and body mass index, for adjustment in addition to model 1 . Model 4 included all the above for adjustments.

prevalence of $H$. pylori infection was higher among diabetic patients than among nondiabetic patients, there was no difference in the regulation of diabetes (28). Therefore, there was no difference in malignancy development between glycemic control groups. Another possible mechanism is a hormonal effect on the development of malignancies. Previous studies have reported that diabetic patients have higher levels of estrogens than nondiabetic patients due to high levels of insulin and insulin resistance $(29,30)$. This elevated estrogens may cause specific cancers, such as uterine or cervical cancer, among female patients $(31,32)$. In terms of male diabetic patients, the increased estrogens may prevent them from developing prostate cancer (33). Although a previous study suggested that poor glycemic control may be related to lower prostate-specific antigen levels (34), the effect of different estrogens levels on glycemic control may be insufficient to prevent or develop cancer. Moreover, lower testosterone levels in diabetic patients may have preventative effects on prostate cancer (35). Similar to estrogens, a previous study has reported a dose-dependent association between glycemic control and testosterone levels (36); however, the effects may be insufficient to affect the development of malignancies.

Summary statistics from national database in Japan reported that age specific all cancer incidence was 21.1 per 1000 for male in their 60s and 18.9 per 1000 for female in their 60s (37). In contrast, incidence rate of all cancer among male was 30.7 per 1000 and that among female was 21.6 per 1000 in our sample. This finding suggests that diabetic patients had higher incidence rate of all cancers compared to general population, which was consistent to previous studies (3).

There are some limitations to our study. First, our data contained only diabetes treatment status, so the types of medication were unknown. Certain medications, such as pioglitazone or metformin, may cause or prevent cancer $(38,39)$. A recent meta-analysis reported that pioglitazone may increase bladder cancer risk 1.13-fold, but this was a not statistically significant effect (38). Metformin may reduce cancer risk by 0.94 -fold, which can be considered a mild effect $(40)$. In addition, sulfonylureas $(41,42)$ or insulin analogs $(43,44)$ have been related to malignancies, but this is still controversial. Therefore, bias caused by the lack of data on patient medication may be minimal. Second, we cannot consider an inverse causality that malignancies change glycemic control. Some patients may develop malignancies without awareness. These malignancies may worsen glycemic control by increasing insulin resistance or may improve glycemic control by reducing appetite. However, every study may have similar issues; therefore, our study is still of value. In addition, our sensitivity analysis excluding those who developed malignancies within 2 years after their first visit may support our results. Moreover, our median follow-up of 1443.5 days may be insufficient to evaluate the development for slow progressive malignancies, such as pancreatic cancer (45). We would report additional development of malignancies after further follow-up. Finally, we cannot take into account potential confounders of HbA1c level, such as

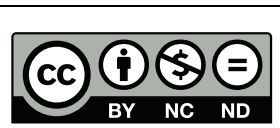

This work is licensed under a Creative Commons Attribution-NonCommercial-NoDerivatives 4.0 International License. 
liver cirrhosis, which may also have effects on malignancy development. However, these confounders may be rare.

\section{Conclusion}

Our study found no association between glycemic control and the development of future malignancies. Compared to a very strictly controlled HbA1c level (5.5-6.4\%), both excessive control $(<5.4 \%)$ and good or bad control (6.5$7.4,7.5-8.4$, and $>8.5 \%$ ) had a statistically similar risk of developing malignancies.

\section{Declaration of interest}

The authors declare that there is no conflict of interest that could be perceived as prejudicing the impartiality of the research reported.

\section{Funding}

This work did not receive any specific grant from any funding agency in the public, commercial, or not-for-profit sector.

\section{References}

1 Tsilidis KK, Kasimis JC, Lopez DS, Ntzani EE \& Ioannidis JP. Type 2 diabetes and cancer: umbrella review of meta-analyses of observational studies. BMJ 2015350 g7607. (https://doi.org/10.1136/ bmj.g7607)

2 Noto H, Tsujimoto T, Sasazuki T \& Noda M. Significantly increased risk of cancer in patients with diabetes mellitus: a systematic review and meta-analysis. Endocrine Practice 201117 616-628. (https://doi. org/10.4158/EP10357.RA)

3 Sasazuki S, Charvat H, Hara A, Wakai K, Nagata C, Nakamura K, Tsuji I, Sugawara Y, Tamakoshi A, Matsuo K, et al. Diabetes mellitus and cancer risk: pooled analysis of eight cohort studies in Japan. Cancer Science 2013104 1499-1507. (https://doi.org/10.1111/ cas.12241)

4 Shikata K, Ninomiya T \& Kiyohara Y. Diabetes mellitus and cancer risk: review of the epidemiological evidence. Cancer Science 2013104 9-14. (https://doi.org/10.1111/cas.12043)

5 Wang C, Wang X, Gong G, Ben Q, Qiu W, Chen Y, Li G \& Wang L. Increased risk of hepatocellular carcinoma in patients with diabetes mellitus: a systematic review and meta-analysis of cohort studies. International Journal of Cancer 2012130 1639-1648. (https://doi. org/10.1002/ijc.26165)

6 Ren HB, Yu T, Liu C \& Li YQ. Diabetes mellitus and increased risk of biliary tract cancer: systematic review and meta-analysis. Cancer Causes Control 201122 837-847. (https://doi.org/10.1007/s10552011-9754-3)

7 Ben Q, Xu M, Ning X, Liu J, Hong S, Huang W, Zhang H \& Li Z. Diabetes mellitus and risk of pancreatic cancer: a meta-analysis of cohort studies. European Journal of Cancer 201147 1928-1937. (https://doi.org/10.1016/j.ejca.2011.03.003)

8 Noto H, Goto A, Tsujimoto T \& Noda M. Cancer risk in diabetic patients treated with metformin: a systematic review and metaanalysis. PLoS ONE 20127 e33411. (https://doi.org/10.1371/journal. pone.0033411)

9 Huang W, Ren H, Ben Q, Cai Q, Zhu W \& Li Z. Risk of esophageal cancer in diabetes mellitus: a meta-analysis of observational studies.

https://ec.bioscientifica.com https://doi.org/10.1530/EC-18-0355 (c) 2018 The authors Published by Bioscientifica Ltd
Cancer Causes Control 201223 263-272. (https://doi.org/10.1007/ s10552-011-9874-9)

10 Ge Z, Ben Q, Qian J, Wang Y \& Li Y. Diabetes mellitus and risk of gastric cancer: a systematic review and meta-analysis of observational studies. European Journal of Gastroenterology and Hepatology 201123 1127-1135. (https://doi.org/10.1097/MEG.0b013e32834b8d73)

11 Marugame T, Sobue T, Satoh H, Komatsu S, Nishino Y, Nakatsuka H, Nakayama T, Suzuki T, Takezaki T, Tajima K, et al. Lung cancer death rates by smoking status: comparison of the Three-Prefecture Cohort study in Japan to the Cancer Prevention Study II in the USA. Cancer Science 200596 120-126. (https://doi.org/10.1111/j.13497006.2005.00013.x)

$12 \mathrm{Xu}$ H, Jiang HW, Ding GX, Zhang H, Zhang LM, Mao SH \& Ding Q. Diabetes mellitus and prostate cancer risk of different grade or stage: a systematic review and meta-analysis. Diabetes Research and Clinical Practice 201399 241-249. (https://doi.org/10.1016/j. diabres.2012.12.003)

13 Jian Gang P, Mo L, Lu Y, Runqi L \& Xing Z. Diabetes mellitus and the risk of prostate cancer: an update and cumulative meta-analysis. Endocrine Research 201540 54-61. (https://doi.org/10.3109/07435800 .2014.934961)

14 UK Prospective Diabetes Study (UKPDS) Group. Intensive bloodglucose control with sulphonylureas or insulin compared with conventional treatment and risk of complications in patients with type 2 diabetes (UKPDS 33). UK Prospective Diabetes Study (UKPDS) Group. Lancet 1998352 837-853. (https://doi.org/10.1016/S01406736(98)07019-6)

15 UK Prospective Diabetes Study (UKPDS) Group. Effect of intensive blood-glucose control with metformin on complications in overweight patients with type 2 diabetes (UKPDS 34). UK Prospective Diabetes Study (UKPDS) Group. Lancet 1998352 854-865. (https:// doi.org/10.1016/S0140-6736(98)07037-8)

16 Action to Control Cardiovascular Risk in Diabetes Study G, Gerstein HC, Miller ME, Byington RP, Goff DC Jr, Bigger JT, Buse JB, Cushman WC, Genuth S, Ismail-Beigi F, et al. Effects of intensive glucose lowering in type 2 diabetes. New England Journal of Medicine 2008358 2545-2559. (https://doi.org/10.1056/NEJMoa0802743)

17 Duckworth W, Abraira C, Moritz T, Reda D, Emanuele N, Reaven PD, Zieve FJ, Marks J, Davis SN, Hayward R, et al. Glucose control and vascular complications in veterans with type 2 diabetes. New England Journal of Medicine 2009360 129-139. (https://doi.org/10.1056/ NEJMoa0808431)

18 Johnson JA \& Bowker SL. Intensive glycaemic control and cancer risk in type 2 diabetes: a meta-analysis of major trials. Diabetologia 2011 54 25-31. (https://doi.org/10.1007/s00125-010-1933-3)

19 Yang X, Ko GT, So WY, Ma RC, Yu LW, Kong AP, Zhao H, Chow CC, Tong PC \& Chan JC. Associations of hyperglycemia and insulin usage with the risk of cancer in type 2 diabetes: the Hong Kong diabetes registry. Diabetes 201059 1254-1260. (https://doi. org/10.2337/db09-1371)

20 Miao Jonasson J, Cederholm J, Eliasson B, Zethelius B, EegOlofsson K \& Gudbjornsdottir S. HbA1C and cancer risk in patients with type 2 diabetes--a nationwide population-based prospective cohort study in Sweden. PLoS ONE 20127 e38784. (https://doi. org/10.1371/journal.pone.0038784)

21 Onitilo AA, Stankowski RV, Berg RL, Engel JM, Glurich I, Williams GM \& Doi SA. Type 2 diabetes mellitus, glycemic control, and cancer risk. European Journal of Cancer Prevention 201423 134-140. (https://doi.org/10.1097/CEJ.0b013e3283656394)

22 Goto A, Noda M, Sawada N, Kato M, Hidaka A, Mizoue T, Shimazu T, Yamaji T, Iwasaki M, Sasazuki S, et al. High hemoglobin A1c levels within the non-diabetic range are associated with the risk of all cancers. International Journal of Cancer 2016138 1741-1753. (https:// doi.org/10.1002/ijc.29917)

23 Casals M, Girabent-Farres M \& Carrasco JL. Methodological quality and reporting of generalized linear mixed models in clinical 
medicine (2000-2012): a systematic review. PLoS ONE 20149 e112653. (https://doi.org/10.1371/journal.pone.0112653)

24 Kashiwagi A, Kasuga M, Araki E, Oka Y, Hanafusa T, Ito H, Tominaga M, Oikawa S, Noda M, Kawamura T, et al. International clinical harmonization of glycated hemoglobin in Japan: from Japan Diabetes Society to National Glycohemoglobin Standardization Program values. Journal of Diabetes Investigation 20123 39-40. (https://doi.org/10.1111/j.2040-1124.2012.00207.x)

25 Lerner N, Shani M \& Vinker S. Predicting type 2 diabetes mellitus using haemoglobin A1c: a community-based historic cohort study. European Journal of General Practice 201420 100-106. (https://doi.org/ 10.3109/13814788.2013.826642)

26 World Health Organization. The International Classification of Diseases. Geneva, Switzerland: WHO,2016. (available at: http://www. who.int/classifications/icd/icdonlineversions/en/)

27 Yamagata H, Kiyohara Y, Aoyagi K, Kato I, Iwamoto H, Nakayama K, Shimizu H, Tanizaki Y, Arima H, Shinohara N, et al. Impact of Helicobacter pylori infection on gastric cancer incidence in a general Japanese population: the Hisayama study. Archives of Internal Medicine 2000160 1962-1968. (https://doi.org/10.1001/ archinte.160.13.1962)

28 Demir M, Gokturk HS, Ozturk NA, Kulaksizoglu M, Serin E \& Yilmaz U. Helicobacter pylori prevalence in diabetes mellitus patients with dyspeptic symptoms and its relationship to glycemic control and late complications. Digestive Diseases and Sciences 200853 2646-2649. (https://doi.org/10.1007/s10620-007-0185-7)

29 Nyholm H, Djursing H, Hagen C, Agner T, Bennett P \& Svenstrup B. Androgens and estrogens in postmenopausal insulin-treated diabetic women. Journal of Clinical Endocrinology and Metabolism 198969 946-949. (https://doi.org/10.1210/jcem-69-5-946)

30 Meyer MR, Clegg DJ, Prossnitz ER \& Barton M. Obesity, insulin resistance and diabetes: sex differences and role of oestrogen receptors. Acta Physiologica. 2011203 259-269. (https://doi. $\operatorname{org} / 10.1111 / \mathrm{j} .1748-1716.2010 .02237 . \mathrm{x})$

31 Sung MK, Yeon JY, Park SY, Park JH \& Choi MS. Obesity-induced metabolic stresses in breast and colon cancer. Annals of the New York Academy of Sciences 20111229 61-68. (https://doi.org/10.1111/ j.1749-6632.2011.06094.x)

32 Yager JD \& Davidson NE. Estrogen carcinogenesis in breast cancer. New England Journal of Medicine 2006354 270-282. (https://doi. org/10.1056/NEJMra050776)

33 Kasper JS \& Giovannucci E. A meta-analysis of diabetes mellitus and the risk of prostate cancer. Cancer Epidemiology, Biomarkers and Prevention 200615 2056-2062. (https://doi.org/10.1158/1055-9965. EPI-06-0410)

34 Atalay HA, Akarsu M, Canat L, Ulker V, Alkan I \& Ozkuvanci U. Impact of poor glycemic control of type 2 diabetes mellitus on serum prostate-specific antigen concentrations in men. Prostate International 20175 104-109. (https://doi.org/10.1016/j.prnil.2017.02.004)
35 Gyawali P, Martin SA, Heilbronn LK, Vincent AD, Taylor AW, Adams RJT, O'Loughlin PD \& Wittert GA. The role of sex hormonebinding globulin (SHBG), testosterone, and other sex steroids, on the development of type 2 diabetes in a cohort of community-dwelling middle-aged to elderly men. Acta Diabetologica 201855 861-872. (https://doi.org/10.1007/s00592-018-1163-6)

36 Ho CH, Jaw FS, Wu CC, Chen KC, Wang CY, Hsieh JT, Yu HJ \& Liu SP. The prevalence and the risk factors of testosterone deficiency in newly diagnosed and previously known type 2 diabetic men. Journal of Sexual Medicine 201512 389-397. (https://doi.org/10.1111/jsm.12777)

37 Foundation for Promotion of Cancer Research. Cancer statistics in Japan 2017. Tokyo, Japan: Foundation for Promotion of Cancer Research, 2017. (available at: https://ganjoho.jp/data/reg_stat/ statistics/brochure/2017/cancer_statistics_2017_fig_E.pdf)

38 Filipova E, Uzunova K, Kalinov K \& Vekov T. Pioglitazone and the risk of bladder cancer: a meta-analysis. Diabetes Therapy 20178 705-726. (https://doi.org/10.1007/s13300-017-0273-4)

39 Zi F, Zi H, Li Y, He J, Shi Q \& Cai Z. Metformin and cancer: an existing drug for cancer prevention and therapy. Oncology Letters 201815 683-690. (https://doi.org/10.3892/ol.2017.7412)

40 Campbell JM, Bellman SM, Stephenson MD \& Lisy K. Metformin reduces all-cause mortality and diseases of ageing independent of its effect on diabetes control: a systematic review and meta-analysis Ageing Research Reviews 201740 31-44. (https://doi.org/10.1016/j. arr.2017.08.003)

41 Yang X, So WY, Ma RC, Yu LW, Ko GT, Kong AP, Ng VW, Luk AO, Ozaki R, Tong PC, et al. Use of sulphonylurea and cancer in type 2 diabetes-The Hong Kong Diabetes Registry. Diabetes Research and Clinical Practice 201090 343-351. (https://doi.org/10.1016/j. diabres.2010.08.022)

42 Hsieh MC, Lee TC, Cheng SM, Tu ST, Yen MH \& Tseng CH. The influence of type 2 diabetes and glucose-lowering therapies on cancer risk in the Taiwanese. Experimental Diabetes Research 20122012 413782. (https://doi.org/10.1155/2012/413782)

43 Hemkens LG, Grouven U, Bender R, Gunster C, Gutschmidt S, Selke GW \& Sawicki PT. Risk of malignancies in patients with diabetes treated with human insulin or insulin analogues: a cohort study. Diabetologia 200952 1732-1744. (https://doi.org/10.1007/ s00125-009-1418-4)

44 Ruiter R, Visser LE, van Herk-Sukel MP, Coebergh JW, Haak HR, Geelhoed-Duijvestijn PH, Straus SM, Herings RM \& Stricker BH. Risk of cancer in patients on insulin glargine and other insulin analogues in comparison with those on human insulin: results from a large population-based follow-up study. Diabetologia 201255 51-62. (https://doi.org/10.1007/s00125-011-2312-4)

45 Nakamura T, Masuda K, Harada S, Akioka K \& Sako H. Pancreatic cancer: slow progression in the early stages. International Journal of Surgery Case Reports 20134 693-696. (https://doi.org/10.1016/j. ijscr.2013.04.040)

Received in final form 15 November 2018

Accepted 29 November 2018

Accepted Preprint published online 3 December 2018 https://ec.bioscientifica.com https://doi.org/10.1530/EC-18-0355 (c) 2018 The authors Published by Bioscientifica Ltd

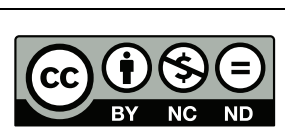

This work is licensed under a Creative Commons Attribution-NonCommercial-NoDerivatives 4.0 International License. 